ITP

21,3

300

Received 30 April 2007

Revised 7 April 2008

Accepted 13 May 2008

\section{Gay men, Gaydar and the commodification of difference}

\author{
Ben Light, Gordon Fletcher and Alison Adam \\ IS, Organisations and Society Research Centre, University of Salford, \\ Salford, UK
}

\begin{abstract}
Purpose - The purpose of this paper is to investigate information communications technologies (ICT)-mediated inclusion and exclusion in terms of sexuality through a study of a commercial social networking web site for gay men.

Design/methodology/approach - The paper uses an approach based on technological inscription and the commodification of difference to study Gaydar, a commercial social networking site.

Findings - Through the activities, events and interactions offered by Gaydar, the study identifies a series of contrasting identity constructions and market segmentations that are constructed through the cyclic commodification of difference. These are fuelled by a particular series of meanings attached to gay male sexualities which serve to keep gay men positioned as a niche market.

Research limitations/implications - The research centres on the study of one, albeit widely used, web site with a very specific set of purposes. The study offers a model for future research on sexuality and ICTs.

Originality/value - This study places sexuality centre stage in an ICT-mediated environment and provides insights into the contemporary phenomenon of social networking. As a sexualised object, Gaydar presents a semiosis of politicised messages that question heteronormativity while simultaneously contributing to the definition of an increasingly globalised, commercialised and monolithic form of gay male sexuality defined against ICT.
\end{abstract}

Keywords Sexuality, Homosexuals, Men, Social networks, Internet

Paper type Research paper

\section{Introduction}

There is a long-standing and well-recognised link between sex and technology throughout history and through many different cultures. Such linkages have shaped the commonly expressed opinion that pornography has fuelled the development of internet technologies, albeit in ways that are difficult to measure given, for example, pornography's underground nature (Lane, 2000) and the generally circumspect manner that sex is discussed in many cultures. With the rise of the internet, and internet dating, we argue that information systems research needs to consider the role of sexuality in shaping such spaces. Indeed, in the UK at least, the popular press reports that internet dating has rapidly become one of the most profitable web services, outstripping the former front runner - pornography (Sunday Times Magazine, 2006). In this paper, we demonstrate how information communication technologies (ICTs) can fuel the online and offline income generation strategies of those providing social networking services to marginal groups in society. We explore this phenomenon via reference to, what we can describe for now as, an internet dating/social networking site for gay men Gaydar.co.uk Our work suggests that Gay men's marginalisation in society may be reinforced through the deployment of strategies based on the commodification of
Information Technology \& People Vol. 21 No. 3, 2008

pp. $300-314$

() Emerald Group Publishing Limited 0959-3845

DOI 10.1108/09593840810896046 
difference. Through this study we emphasise the links between gender, sexualities and ICTs in order to demonstrate the value of, and the need for, greater attention to men's gendered experiences and sexuality within information systems research.

Mirroring the literature on gender debates (Davis et al., 2006), there are a variety of arguments concerning the basis of sexuality (variously biological, social or cultural), encouraging debate on which sexualities are to be seen as legitimate (usually those defined as heterosexual) and the extent to which gender influences sexuality, and vice versa (Beasley, 2005; Weeks, 1985). We see sexuality as concerned with sexual object choice and desire (Cranny-Francis et al., 2003). Within the information systems domain, existing research, for a variety of potential reasons, does not generally theorise gender and sexuality, and when it does, only women's gendered experiences are subject to theoretical scrutiny (Adam et al., 2004)[1]. Information systems oriented gender research lacks serious theorised attention to men's experiences - resulting in men tending to be "black boxed". This reflects the perennial issue in research on gender, in that gender appears to attach to women but is not seen to influence or impact upon men (Faulkner, 2002). Moreover, information systems research is predominantly, although not exclusively (Trauth, 2002), heteronormative in nature - that is gender is considered in heterosexual terms alone, where heterosexuality is tacitly regarded and accepted as the norm. For example, women are often considered in relation to a "typical" family unit comprising one male and one female parent with one or more children. Gender and sexuality can be therefore be seen as separate parts of a set of things that interweave at many points, a system of cultural logic that is combined with many other components to form a fully articulated social identity (Rubin, 1984). Everyone therefore, has a stake in the meanings and identities defined through sexuality irrespective of their sexual orientation. Indeed, it is claimed that assumptions and norms associated with sexualities intimately contribute to the definition of contemporary culture and society (Person, 1980).

With Gaydar forming the source of material for our empirical study, we argue that a fruitful analysis of gender, sexuality and information systems may be made through a combination of the literature on the commodification of difference (Magnet, 2007) and inscription within technological artefacts (Akrich, 1992). In this study, we are focusing on gay male sexuality but it is far from our intention that this should stand for all types of sexuality. We are conscious that a study involving lesbian sexuality may well highlight very different concerns. This reinforces our argument that there is a paucity of research on sexuality in relation to research in IS, bolstering our call for more research in this area. Although, on the face of it, theoretically disparate, our two analytical lenses focus and intersect along a strongly political dimension and this intersection offers potential for valuable insights. This perspective is available because views or conceptions of the user can be inscribed into technological devices, and products, forming a script of an anticipated user's actions. Where there is an anticipated difference from a tacit cultural norm this may be seen as an opportunity for niche marketing (Chasin, 2000).

Reinforcing the political dimensions of the commodification of difference, albeit in terms of ethnicity rather than sexuality, Magnet (2007) describes the toy manufacturer, Mattel's decision to market a "black Barbie" identical to its main Barbie product range but using tinted plastic and a change of costume. Magnet (2007, p. 594) claims:

Mattel signified ethnicity with tinted plastic and a change of costume - simply representing their signature white doll in a racialised form but never going so far as to "break the mould" and attempt to produce a diversity of representation.

\section{Gay men, Gaydar and difference}

301 
ITP

21,3

302
The implication of this niche commodification is that the meanings conveyed by "Barbie" are skin-deep, easily interchanged to suit specialised markets and have new meanings supplanted without negative connotation. More subtly, "black Barbie" engages its consumers in a circuit of political meaning that effaces ethnic distinction, propagates issues of unrealistic body image while subsuming them into a still wider series of mainstream norms and acceptances.

The language of "inscription" is also important in our analysis. Akrich (1992) describes the way in which technological objects define users and the relationships between users and technological artefacts which is, at least to some extent, a function of decisions made by designers. This forms a script of the expectation that the designer has of the way that a user will engage with the artefact. In the vocabulary of "inscription", "delegation" is a related term signifying that designers of technology may design in particular delegations of behaviour to the user or to others. Designers make decisions about what should be delegated and to whom it is to be delegated and this produces "a specific geography of responsibilities" (Akrich, 1992, p. 207). Akrich also argues that moral judgments are made in this process. Hence "inscription" and "delegation" do not just signify a set of purportedly neutral behaviours surrounding technological artifacts, they have moral and political dimensions. Designers "inscribe" a view of the world, within the technical content of new artefacts. As she notes, the adjustment between the user imagined by the designer and the real user sometimes results in unexpected things. Designers may have views as to how their users will behave but users can resist these imposed structures, intentionally or otherwise. Actors can be enrolled. Latour (1997) describes the way in which seat belts are technological devices to which we have delegated morality with an inscribed view of users who will not belt up unless forced to do so by the warning alarms, lights and voices which are part if the design of modern automobiles. The developments of social networking technologies, in their many variants, similarly inscribe specific understandings of the social world and act to enrol users in specific ways. The Facebook/Friendster form of enrolment focuses on the gathering of "friends" while simultaneously redefining the received understanding of what friendship means and the expansiveness with which this term can be applied.

In making our analysis we shed light on the co-production of gay men and their sexualities through the design and application of the sociotechnical brand of Gaydar (online and offline) with its inscribed views of gayness. Such conceptions of gayness may be stereotypical and defined against a heterosexual norm, rather than intersecting with complex identities that include multitudinous forms of gender and sexuality. Whilst the view of the user or a particular behaviour inscribed in such sociotechnical arrangements may, on the face of it, be constraining, we argue that technology is often used in ways which the original designer never intended (Wajcman, 1991; Fleck, 1994; Stewart and Williams, 2005) and an acknowledgement of this steers the analysis away from the narrow frameworks of technological determinism.

\section{Discourses on social networking: community and commodity}

In the light of the furore around social networking sites such as Friendster, MySpace, Bebo and Facebook, it is all too easy to view the behaviours and activities associated with these spaces as new. However, in the broad light of day, when we talk about social networks we are talking about social relations between people who have some type of 
relationship or affiliation (Wellman, 1996). In this sense, social networking technologies merely provide ICT support for such activities. Prior technologies including the multitude of applications on the internet (such as chat rooms and online games) mobile phones, landline-based telephones all hold, and continue to hold the potential to facilitate social networking. However, it is the range of features and capabilities inscribed within individual social networking sites that have captured the public's imagination and have led to them being marked as different or even new. Such 303 features involve the creation of profiles, which in addition to text, images, and video created by the member, also contain comments from other members, and a public list of the people that one identifies as friends within the network (boyd, 2008). Indeed, it has been argued that the ability to see who has "petted" you through a Facebook application has led to this behaviour being afforded the label of "social grooming for the information age" (Donath, 2007). Yet, boyd (2008) also notes that such tight definitions are problematic - social networking technologies can take many forms. Friendster, for example, evolved into what is now described as a social networking site from its origins as an internet dating site. The other influence that has made social network technologies popular news is the link made with sexual deviancy. The gay personals section of the French Minitel system is an early example, it was labelled an "electronic brothel" and condemned by several public figures as a venue for the seduction of boys (Livia, 2002). Recently, around 30,000 registered USA sex-offenders have been removed from MySpace amidst moral panic concerning sexual predators on the site, despite the counter argument that the proliferation of these activities is exaggerated (Bahney, 2006; Fox News, 2007; boyd et al., 2007).

To date, the majority of sociotechnically-oriented research in this area has focussed upon how members of social networking sites make such spaces work for them in situ and how they integrate such spaces into their daily lives (e.g. boyd, 2008; Larsen, 2007). There is, however, a small, but significant body of literature that considers commercial interests in such spaces. Arvidsson's (2006) work on Match.com is closely related to Gaydar's form of social networking. This work identifies the self-inscription activities of participants as being acts that generate surplus value for the organisation - the original inscriber - in the form of market (and marketable) data. This type of labour can also be readily identified in other situations online (for example eBay and SecondLife) and offline (speed dating events and even the UK tradition of car boot sales). In each case the owner of the network relies upon members to generate profit. Arvidsson sees the surplus value generated through Match.com as being a result of its branding strategy and brand management that controls and shapes individual expectations about the Match.com experience and the range of social networking possibilities that can be found through this specific website. Campbell's (2005) study of PlanetOut similarly points to the Janus quality of internet affinity portals in terms of the tensions between the member's need for privacy and the corporate need for consumer data. As has been noted generally, commercially oriented online spaces' privacy policies tend to serve the marketing wishes of owners rather than that of their consumers, meaning that personal data is becoming subject to increased commercial interest and pressure (Fernback and Papacharissi, 2007; Röhle, 2007). All of this is reminiscent of the rhetoric surrounding database marketing in the 1980s. Yet, what is interesting to date is that there is a lack of multi-site studies of social networking arrangements. The tendency is to examine networking within a single site and 
ITP

21,3

304 examine its relationship to offline activities (Baym, 2007; Hargittai, 2007; Lange, 2007). This critique can be levied at studies concerning the social enactment achieved at social networking sites as well as studies of the commercial interests that influence these sites. Attention to the multi-sited nature of social networking is important given our attachment to the notion of inscription. Boyd states that a MySpace profile can be seen as a form of digital body where individuals write themselves into being, but one which is regulated by offline social hierarchies (boyd, 2006). Following Surden, who talks of the ability to write yourself into being on such sites, boyd takes this further by suggesting that "friending" writes communities into being (boyd, 2006). However, as Kendall (2007) concludes from her study of Live Journal, there can be tensions between efficiency (blending social contacts) and audience management (creating diverse presentations of self). She argues that we are accustomed to behaving differently with different groups of people and providing different performances in different situations. Thus, if we examine the role of social networking sites in conjunction with other sites of networking (not necessarily those that are technologically mediated) then the possibilities for writing communities into being become further extended. This is the locus of our work. Through the use of Gaydar.co.uk individuals write a version of themselves and of this gay community into being. However, because of the desire to commodify "the difference" that is gay, predominantly white men, online and offline, such inscriptions become monolithic caricatures that are obdurate and enrol even those who do not participate in such arrangements at all or only by proxy.

\section{Gaydar and the commodificaiton of difference}

Gaydar is a colloquial term premised on having the capability to locate and work out if a person is gay - a form of "gay radar". Therefore, the use of the term for the Gaydar group of web sites, of which one of the inscribed aims is to assist people to locate each other through a technologically mediated "gaze", seems appropriate. Gaydar operates in around 159 countries but in this paper, we focus primarily on the UK-oriented experience.

In terms of our research approach, Light, a gay man, has undertaken an ethnography (Myers, 1999), having been a member and active participant in the network online and offline since December 1999, very soon after it was launched as a basic chat room. As Halberstam (2003) notes, researchers may coexist in the same friendship networks and may function as co-conspirators. Data collection involved participant observation of the software in use, analysis of the functionality and content of the site, and the site of the Gaydar developers, Qsoft. We have also drawn on documentary evidence, such as media packs, as provided by Qsoft, and advertising media. Indeed, the use of advertising imagery is one of the most popular forms of photographic evidence used in social research (Ali, 2004). Adam and Fletcher have been further involved in the interpretation and analysis of this data. Mindful of the ethical considerations for internet associated research, we have not studied individuals (Brownlow and O'Dell, 2002; Ess and AoIR Ethics Working Commitee, 2002; Carter, 2005). We have approached Gaydar as an artefact that is informed by and influences contemporary cultural and social attitudes and beliefs. We have made a conscious decision not to reproduce quotes from private member profiles, or members themselves, to ensure that no "private" data are made unwittingly or unnecessarily made "public" for arguably marginal benefit. 


\subsection{Introducing QSoft}

The company that developed and operates Gaydar is called QSoft. It was started in November 1999 by a gay male couple and QSoft now provides services targeted at accessing the "gay market". In 2006-2007, it was awarded "cool brand" status. In its promotional case material it stated of the Rainbow Network[2]:

The network sets out to target the gay market at different times of the day and at different times in people's lives. This means that advertisers and brands, looking to target the gay and lesbian audience, now have a time and cost-effective one stop shop, through which to do it (www.superbrands.easysite.org/files/Gaydarcouk_4087.pdf).

The pages of QSoft's web site make the commercial interpretation of Gaydar clear. Statistics are used extensively, alongside rhetoric about why organisations should market their products and services through banner advertising and sponsorship. Such rhetoric is supported by the management personnel employed by QSoft who place primary emphasis on their advertising and marketing backgrounds (www.qsoft.co.uk/ content/about_management.aspx) and by the company claims that 81 per cent of their "audience" fall into the $\mathrm{ABC1}$ demographic (www.qsoft.co.uk/content/advertising. aspx). Gay men in particular are singled out to the extent that the usual acronym for the Lesbian, Gay, Bi and Trans community (LGBT) is replaced on the QSoft website's FAQ section with GLBT (www.qsoft.co.uk/content/about_faq.aspx). This suggests that difference, in the form of sexuality considered to be outside an established norm, may be encouraged and publicly articulated, to the extent that it represents a commercial marketing opportunity. Indeed QSoft have stated:

this is a significant sector, which regardless of social stature is willing to spend well above its means. This makes the GLBT audience a real advertising destination for brands (www.qsoft. co.uk/content/advertising_outright.aspx).

These claims are made despite arguments that the resources of such a market are overemphasised (Campbell, 2005) and that the meanings and identity of being a gay male are not universal (Binnie, 2004). In August 2007, a press release[3] was issued by QSoft as a response to Light's (2007) study which suggested that Gaydar potentially, could marginalise and stereotype users through its profiling system. This was taken up by PinkNews.co.uk, who asked QSoft to comment. They did not believe they were perpetuating such a distorted image of the LGBT community stating:

There is no need for us to change the way in which we offer categorizations to our members. They are based upon extensive research into what our users say they want us to provide. If users felt marginalized by the system, rest assured they would be the first to tell us so. We are constantly researching the views and requirements of our community of users via focus groups and research programmes such as Outright 2006.

The "gay market" is also posited as a lever into the "mainstream" (straight) market. In a previous incarnation of QSoft's web site the following claim was made:

[Why Target the Gay Market?] Because you want the Mainstream Market. The gay consumers friends and family are part of the wider community. Who better to target as an ambassador [f]or your product than the person in the group with the money to purchase and the inclination to innovate?[4]

\section{Gay men, Gaydar and difference}

305 
ITP

21,3

306
From a member's perspective the privacy policy[5] of Gaydar illuminates the sources of some of this information. It states:

Some general statistical information about the Site User base, sales patterns, traffic volumes and related matters may be passed on to reputable third parties but these details will not include information personally identifying You.

Arvidsson argues that the surplus value generated through Match.com is a result of its branding strategy and brand management that controls and shapes individual expectations about the Match.com experience and the range of social networking possibilities that can be found through this web site. Gaydar's sites are not dissimilar in this respect in that, they have a rigorous brand management strategy thoroughly extricated in a document titled "id entity"[6]. The brand control document for Gaydar does far more than police a brand. The cover image of the brand control document, depicts a young man who has visible muscular tone, a tribal tattoo on his right arm, a pierced nipple and a singlet pulled over his head but still wrapped around his shoulders. The other image, which covers the Gaydargirls brand, incorporates three woman varying in apparent age, all smartly dressed. Although the central woman is wearing glasses, a studded belt and a short $\mathrm{t}$-shirt with her midriff exposed she gives the impression of "middle-class student" rather than "rough punk". Both images conform to particular stereotypes of sexualised identity without this being explicitly claimed by the document. QSoft Consulting continue this visual theme through their web material, with highly posed and "Vogue"-like compositions.

Although Gaydar is largely unknown outside the gay "community", according to QSoft, Gaydar has over 4.2 million members worldwide with over 1.2 million of these being based in the UK. QSoft reports that the site consistently receives more traffic that mainstream sites such as RyanAir and Marks \& Spencer[7]. Indeed it is argued that the Gaydar radio station and associated web sites now reach more than 85 per cent of the UK gay and lesbian marketplace. The majority of Gaydar's members are gay and bisexual men. There are some gay women, bisexual women, transsexual, transgender and transvestite members, but these are in the minority. The sister site, www.gaydargirls. com, launched in 2002, now has over 250,000 registered members. Access to Gaydar is via registration and whilst this is free to guest members, extra services can be obtained by upgrading to member status for around $£ 60 / € 77$, or the equivalent, per year.

\subsection{Making a difference through technological inscription}

QSoft continuously enrols advertisers whose specific visual and textual representations of sexuality conform to and confirm specific meanings of attractiveness and affluence. The enrolment necessarily commodifies the sexuality of individual members and in doing so encourages these members to reflect on the extent to which they reveal themselves and their identities. Visual physical comparisons are inevitably available to be made, not just against archetypes of male heterosexual masculinities but also against the archetype of gay masculinities that Gaydar itself systematically and publicly inscribes (Rogers, 2005). The social network of Gaydar draws out a type of gay masculinity that provokes direct and personal comparison and encourages those members who are not $\mathrm{ABC} 1$ with chiselled features to be more carefully circumspect than those who fulfil this acceptable model of commodified identity. 
To be part of the Gaydar community it is necessary to construct a personal profile. The software used to create member profiles is configured by the member based on drop-down menus, tick boxes and some free text. Not surprisingly, we find dominant cultural stereotypes reproduced and reinforced through technological design. This is not to suggest that there is any conspiracy to "simply" part gay men from their money but rather that design choices inscribed within the technology may reinforce a stereotype that is defined with reference to a collective cultural norm of what being a gay man means. In seemingly denying the politics of difference, this is itself a politically charged stereotype in the way that it constrains expressions of difference. For example, a drop-down menu of the sub-categories of gay male identity offered by Gaydar generally precludes variations, combinations, even greater categorical accuracy or even resistance to this form of identification. The profile created can be very detailed and results in the intended and unintended categorisation of member into groups with identities that are well known within the gay community. Configuring the profile requires the creation of a member name, the input of member status, what the member is using Gaydar to look for and a geographic location. Permutations might be a single gay man, based in Salford, UK, looking for a relationship or a gay couple looking to meet friends in Leeds, UK. The kind of optional data that can be input is extensive and ranges from physical attributes such as hair colour through to sexual and non-sexual activity preferences. There are also free text spaces for members to write about themselves and what they like to see in others. Although the free text element implies freedom to define oneself as one chooses, the presence of menus and tick boxes shapes a pre-defined notion of what may or may not be an acceptable expression of identity. This approach to the definition of identity is true for many sites where membership profiles are created and maintained and is, perhaps unwittingly, a key way of constraining and categorising membership and a key way in which a constrained set of inscriptions of sexuality are signalled.

It is important to note the lack of user involvement in Gaydar's development trajectory. As a member of the site, Light has also been a member of the site's user group, but has only ever been asked to comment upon complete products, rather than detailed screen layouts or functionality requests. This approach to site development appears to confirm the supposition that the form and content of Gaydar is based around the developers' conceptions of what it means to be a gay man. In effect, particular views of gayness are being inscribed into Gaydar by the designers of the system.

\subsection{Commodifying intimate social engagement}

A further strand of commodification that is woven into Gaydar is exemplified by the presence of male escorts. The presence of male escorts in Gaydar is somewhat more problematic beyond the profit motivations of the sale of sex (or at least the suggestion of this possibility). It could be argued that Qsoft condones (and profits from) an albeit veiled form of commercial sex - the site has chat rooms for escorts to operate and charges commercial membership rates. As a result the site implicitly offers comment about the selling of sex in general and about the perception that differences exist between male and female as well as opposite-sex and same-sex forms of escort activity. The implication could be drawn that same-sex male escort work is a "milder" or perhaps even less morally concerning activity. At the very least, the presence of escort

\section{Gay men, Gaydar and difference}

307 
ITP

21,3

308 services indicates that Qsoft believes that its niche market will tolerate and even purchase such services. Escort activity draws the site into a debate about the political meanings associated with the commodification of sex, as well as an uneasy tension of sex-for-sale being located amongst the broader range of social engagement activities that Gaydar facilitates. Ultimately, Gaydar is inscribed as a place and facilitator of sexual activity highlighting the commercially sexualised nature of Gaydar itself although not so crudely as to be reduced to being a sex "thing".

However, Gaydar represents an amalgam of responses, understandings and attitudes that may not individually rest with any single developer, male escort or website member. We are not saying that gay men condone escort activity, although it would be all too easy to think otherwise given that in one UK marketing report, gay men are taken to be a homogenous promiscuous group who cannot live without the supporting tools of the mobile phone and internet chat rooms (Anderson et al., 2002). Indeed, the presence of health promotion workers, sits alongside these other opportunities offering a common interpretation of gay male sexuality - that gay men are promiscuous and that the incidence of the HIV virus, in the UK at least, is higher than in the heterosexual population. In the face of this there are tensions in regard to how safe a web-based environment may be viewed given that other studies have indicated such groups favour social networking sites over traditional meeting places such as bars (Bolding et al., 2004). In many respects Bolding et al.'s conclusion is founded upon assumptions regarding the anonymity of web site interactions - or at least the ability to remain anonymous whereas we argue that Gaydar demands specific types of interaction and engagement that conforms to the series of sexualised meanings that have developed around its creation and development. However, the presence of escort activity in Gaydar could also be seen as a delegation of morality akin to that described by Latour (1997) in relation to seatbelts and Adam et al. (2004) in relation to the proposed UK children's database. While there is nothing that says that the developers of Gaydar explicitly condone escort activity, the design of the site greatly facilitates such activity and provides a source of profit for QSoft, therefore it is not unreasonable to claim that Gaydar represents a moral position that condones escort activity inscribed into its design.

\subsection{Extending the Gaydar brand}

Gaydar reveals a specific relationship to prevailing social structures with its contribution to a particular commodification of difference project that itself has a wider relationship to the heteronormative attitudes integral to social spaces, including the internet, but extending more broadly to other spaces including entertainment venues and "abroad". The commercial expansion of Gaydar as an online travel agency (Gaydar Travel, launched July 2005, and Gaydar Days), for example, further provides evidence that the relationship may be conceived, by the developers, as being a commercial niche market. Gaydar is well positioned to take advantage of such a market - as many of its marketing efforts, as we illustrate earlier, claim. Indeed, QSoft's pitch is arguably a more subtle and finessed version of mainstream attempts at tapping into this market. As one airport bookstall offering states: "If your company is not welcoming gay travellers, you'd better get moving because you are losing lots of money and market share" (Guaracino, 2007, p. xviii). Again, the power and rhetoric surrounding notions of the pink pound are being brought into play to commodified sexuality and gender in a systematic manner. 
Emphasis on travel as a key leisure activity of contemporary gay culture is also reflected in the sponsorship of the Sydney Mardi Gras by one of the Gaydar web sites. This similarly reflects the role of Gaydar in addressing and commodifying a niche marketing with assumptions regarding the propensity of members to travel internationally and their shared interest in a specific public event. This sponsorship represents a thoroughly mainstream capitalist endeavour that gives a certain type of recognition and political articulation of the multiple identities that individuals maintain while also confirming heteronormative assumptions regarding the affluence of the gay community. The assumption is that because of a person's sexuality they are likely to have a higher disposable income because, for example, they have no commitment to children. The sponsorship of the Sydney Mardi Gras by Gaydar can therefore be seen as tacit support for a specific range of sexualities that do not simply recognise Australian national identity (or even sexualised identity) but rather represents a commodity of desire that finds favour with specific members of the Gaydar community.

The development of the Gaydar Radio Station similarly reveals the meaningful extension of Gaydar's influence into areas where the bias and heteronormative power of the mainstream has been widely recognised and critiqued. Gaydar Radio again develops a specific rationale for why a distinct form of media is required in this context. The implication - and again it is one based around specific notions of sexuality - is that gay men will prefer to listen to specific genres of music in preference to those presented on national or commercial broadcasters. Gaydar Radio sponsored the London [gay] Pride event in 2006 as did another gay internet dating site Gay.com. Irrespective of the political messages that can be presented in between musical tracks the association of media content to a specific inscription of sexuality is perhaps an oversimplification of the individual relationship that exists between musical taste, sexuality and the vast range of other factors that constitute individual identity. This is another example of the tensions and negotiations that are found in Gaydar's continual inscription of a specific form of sexuality as "the" gay male sexuality.

\subsection{Extending the reach of Gaydar}

QSoft have two joint nightclub ventures in London's Soho area and internet-enabled computers have also been placed in other gay bars and nightclubs effectively extending the places in which Gaydar is present. The location of Gaydar terminals outside of a home (or possibly work) environment also moves the inscribed community outwards along with its specific commodification of gay male sexuality. Gaydar, and the meanings that are bundled with it, is presented within the context of a specific aspect and activity of gay male sexuality - the bar or nightclub - which itself is representative of specific forms of sexuality and specific forms of commercialism. The environment is influenced by the Gaydar presence by offering an extension of possibilities for social engagement that an individual can achieve in any single night. The Gaydar presence also reshapes the bar/nightclub environment by encouraging individuals to remain longer in a single venue consequently supporting the opportunities for commercial profit while simultaneously throwing up the potential tension that bar and club-goers utilising the terminals may be less engaged with the physical space.

\section{Gay men, Gaydar and difference}

309 
ITP

21,3

310
Gaydar is also present in other environments and websites through the creative use of the iconic symbol associated with Gaydar - which is policed through its branding documentation. Gaydar members link to and identify with the community by downloading banners and buttons that they paste onto their web pages. This button creates a network of association with the associated political and commercial meanings of Gaydar as well as being more mundanely a referral network. The popularity of Gaydar is masked by the lack of words on the link buttons and images with the Gaydar message being conveyed entirely through the symbolic value of the button and requiring pre-existing knowledge of Gaydar and its network of web sites - in effect an individual must already "be part of the club" to understand the value and associated meanings of a Gaydar button on another web site. The exclusive use of symbolism will also generally preclude "random" clicks by uninformed web users suggesting that gaining knowledge of Gaydar itself requires something more than a single click. This symbolism has been transferred to clothing. Gaydar t-shirts have are available which include a member's profile name. Indeed, in a recent copy of $A X M$ magazine, it was stated that gay men are now more likely to be asked for, and give out, their Gaydar profile name than their telephone number.

Gaydar's presence in other environments has also extended to the most ubiquitous forms of technology. The Gaydarmobile service for instance, allows members to appear online and access the service via a mobile phone. This service even uses member inputted postcode data to pinpoint other members on the move via GPS - the Gaydar Positioning System.

The terms of the Gaydarmobile offer make the audience and purpose, as well as the costs, explicitly clear:

All Gaydar members and guests are "Pay As You Cruise" (PAYC) users on GaydarMobile. Once you top up your account with $£ 3.00$ of credit you can read and send messages, search for guys in your favourite bar or venue and download pictures. Most "events" are charged at $5 \mathrm{p}$, and anything you update or change on your GaydarMobile is automatically updated on your Gaydar profile and vice-versa (see www.gaydar.co.uk/mobile).

All of these "extensions" of Gaydar carry the specific meanings and inscriptions associated with the original site. This has the effect, in turn, of at least partially inscribing these meanings onto the spaces and places that become associated with Gaydar. If, as we argue, the Gaydar view of gay male sexuality is only one form of sexuality among a multitude of many possibilities this implies that the Gaydar version ultimately reinforces a specific and increasingly mainstream cultural interpretation regarding gay male sexuality that continues to be constructed and reinforced with the success of the Gaydar site itself.

\section{Conclusion}

Through our aim to make a number of differing contributions to the fields of information systems research we offer a series of specific conclusions as well as observations for further study. First, we place sexuality, as a social category, centre stage and theorise it using the literatures of gender and sexuality studies. We note that the literature of inscription can be pressed into service to describe the ways in which a website, such as Gaydar, can reinforce stereotypes of gay males and effectively commodify difference. We also provide insights into the contemporary phenomena of social networking - in this case the purpose being, primarily, internet dating. In 
combination we use these approaches to help us bring to the surface a cultural logic that is not obvious at first glance as to why several seemingly ad hoc areas of social and cultural activity are tied to a sexually charged social networking site. It also allows us to pay attention to the tensions amongst commercial interests and identity formation, particularly as they relate to sexualities. In sum, we argue that the meanings attached to gay male sexualities influence the development trajectory of Gaydar and its associated services.

The commodification of difference, in the context of Gaydar, operates through a series of tensions that bring together the need to manage complexity, in a technical sense, the personal management of individual identity, the need to present a marketable media entity and the desire to utilise technology to meet personal needs rather than to support commercial objectives. The tension is emphasised because it is the commercially-oriented developer that has initially written the community into being. However, it is the management of individual identity - the individual inscribing of self, including individual difference - that perpetuates and extends the community. The inscribed individual may in turn be antithetical to the aims of the marketable media entity, not an exemplar of an $\mathrm{ABC} 1$ demographic, not a categorical or marketable identity and consequentially not readily represented by the Gaydar commodity.

By comparison, we note Napster's ultimate domestication and containment at the hands of the recording industry was not disruptive in the permanent sense. This is akin to the way that Gaydar has minimally disrupted notions of "gayness" given its attachment to niche marketing reinforcing stereotypes. This is important as it may be drawn upon as a political reference point. For example, Al Gore drew upon a Napster metaphor to describe the American democratic system as a way to "tap into" voters (Spitz and Hunter, 2005). Thus Napster (and Gaydar) can be seen as a potentially political as a tool that can be enrolled to wield power in a real social sense.

As Walsham (2000) sets out in his agenda for research on globalisation and IT, there is a need for a multi-level analysis of the phenomenon which will have profound effects on self identity that will not be uniform. Sexuality, we would argue, is a critical consideration in this light. Gaydar is a worldwide phenomenon and thus, as an enabler of groups of communities, it is an important technology to consider in relation to the globalisation of sexuality, and more directly the globalisation of specific forms of sexuality. This area, including consideration of other internet dating communities, requires further work as few studies have examined how organisational identities are constructed through processes of interaction with outsiders. Still less attention has been paid to those multiple and intersecting web-based locations where sexual identity-work takes place. Finally, considering difference more broadly, further interesting insights may be gained by employing theoretically informed explorations of other communities which are socially stratified by categories such as gender, ethnicity, sexuality and disability.

\section{Notes}

1. Light's (2007) and Fletcher and Light's (2007) earlier works on Gaydar being exceptions.

2. The Rainbow Network is QSoft's umbrella organisation for Gaydar and its associated services such as Gaydargirls and Gaydar Radio.

\section{Gay men, Gaydar and difference}

311 
ITP

21,3

312
3. The Press release can be found at: www.salford.ac.uk/news/details/559 and the article in PinkNews.co.uk can be found at: www.pinknews.co.uk/news/articles/2005-5221.html

4. www.qsoft.co.uk/mediapack/online.html (no longer accessible)

5. Accessible via the front page of Gaydar.co.uk

6. Gaydar brand guidelines accessed at: www.qsoft.co.uk

7. The Latest Media Pack for Gaydar can be accessed via www.qsoft.co.uk

\section{References}

Adam, A., Howcroft, D. and Richardson, H. (2004), "A decade of neglect: reflecting on gender and IS”, New Technology, Work and Employment, Vol. 19 No. 3, pp. 222-40.

Akrich, M. (1992), "The de-scription of technical objects", in Bijker, W.E. and Law, J. (Eds), Shaping Technology/Building Society: Studies in Sociotechnical Change, MIT Press, London.

Ali, S. (2004), "Using visual materials", in Seale, C. (Ed.), Researching Society and Culture, Sage Publications, London.

Anderson, B., Gale, C., Gower, A.P., France, E.F., Jones, M.L.R., Lacohee, H.V., McWilliam, A., Tracey, K. and Trimby, M. (2002), "Digital living: people-centred innovation and strategy", BT Technology Journal, Vol. 20 No. 2, pp. 11-29.

Arvidsson, A. (2006), "'Quality singles': internet dating and the work of fantasy”, New Media and Society, Vol. 8 No. 4, pp. 671-91.

Bahney, A. (2006), "Don't talk to invisible strangers", New York Times, available at: www. nytimes.com/2006/03/09/fashion/thursdaystyles/09parents.html (accessed 26 November 2007).

Baym, N.K. (2007), "The new shape of online community: the example of swedish independent music fandom”, First Monday, Vol. 12 No. 8, available at: www.firstmonday.org/issues/ issue12_8/baym/index.html

Beasley, C. (2005), Gender and Sexuality: Critical Theories, Critical Thinkers, Sage Publications, London.

Binnie, J. (2004), The Globalization of Sexuality, Sage Publications, London.

Bolding, G., Davis, M., Sherr, L. and Hart, G. (2004), "Use of gay internet sites and views about online health promotion among men who have sex with men”, AIDS Care, Vol. 16 No. 8, pp. 993-1001.

boyd, d.m. (2006), "Friends, friendsters, and top 8: writing community into being on social network sites", First Monday, Vol. 11 No. 2, available at: http://firstmonday.org/issues/ issue11_12/boyd/index.html

boyd, d.m. (2008), "Why youth $\bullet$ social network sites: the role of networked publics in teenage social life", in Buckingham, D. (Ed.), Youth Identity and Digital Media, MIT Press, Cambridge, MA.

boyd, d.m., Finkelhor, D., Lenhart, A., Lordan, T. and Ybarra, M. (2007), Just The Facts about Online Youth Victimization: Researchers Present the Facts and Debunk Myths, Internet Caucus Advisory Committee, 5 March, available at: www.netcaucus.org/events/2007/ youth/20070503transcript.pdf (accessed 27 November 2007).

Brownlow, C. and O'Dell, L. (2002), "Ethical issues for qualitative research in on-line communities", Disability and Society, Vol. 17 No. 6, pp. 685-94.

Campbell, J.E. (2005), "Outing PlanetOut: surveillance, gay marketing and internet affinity portals", New Media and Society, Vol. 7 No. 5, pp. 663-83. 
Carter, D. (2005), "Living in virtual communities: an ethnography of human relationships in cyberspace", Information Communication and Society, Vol. 8 No. 2, pp. 148-67.

Chasin, A. (2000), Selling Out: The Gay and Lesbian Movement Goes to Market, St Martin's Press, New York, NY.

Cranny-Francis, A., Waring, W., Stavropouos, P. and Kirkby, J. (2003), Gender Studies: Terms and Debates, Palgrave Macmillan, Basingstoke.

Davis, K., Evans, M. and Lorber, J. (2006), Handbook of Gender and Women's Studies, Sage, London.

Donath, J. (2007), "Signals in social supernets", Journal of Computer-mediated Communication, Vol. 13 No. 1, available at: http://jcmc.indiana.edu

Ess, C. and AoIR Ethics Working Commitee (2002), "Ethical decision-making and internet research: recommendations from the AOIR Ethics Working Committee, approved 27 November 2002", available at: www.aoir.org/reports/ethics.pdf (accessed 1 November 2005).

Faulkner, W. (2002), "The power and the pleasure?A research agenda for 'making gender stick", Science, Technology and Human Values, Vol. 25 No. 1, pp. 87-119.

Fernback, J. and Papacharissi, Z. (2007), "Online privacy as legal safeguard: the relationship among consumer, online portal, and privacy policies”, New Media and Society, Vol. 9 No. 5, pp. 715-34.

Fleck, J. (1994), "Learning by trying: the implementation of configurational technology", Research Policy, Vol. 23 No. 6, pp. 637-52.

Fletcher, G. and Light, B. (2007), "Going offline: an exploratory cultural artifact analysis of an internet dating site's development trajectories", International Journal of Information Management, Vol. 27 No. 6, pp. 422-31.

Fox News (2007), "Creator of MySpace sex offender database is excop", Data Expert, available at: www.sentryweb.com/articles/myspacefox.pdf (accessed 28 October 2007).

Guaracino, J. (2007), Gay and Lesbian Tourism: The Essential Guide for Marketing, Butterworth-Heinemann, Boston, MA.

Halberstam, J. (2003), "What's that smell? Queer temporalities and subcultural lives", International Journal of Cultural Studies, Vol. 6 No. 3, pp. 313-33.

Hargittai, E. (2007), "Whose space? Differences among users and non-users of social network sites", Journal of Computer-mediated Communication, Vol. 13 No. 1, available at: http:// jcmc.indiana.edu/voll3/issue1/hargittai.html

Kendall, L. (2007), "'Shout into the wind, and it shouts back' identity and interactional tensions on LiveJournal", First Monday, Vol. 12 No. 9, available at: http://firstmonday.org/issues/ issue12_9/kendall/index.html

Lane, F. (2000), Obscene Profits, Routledge, London.

Lange, P.G. (2007), "Publicly private and privately public: social networking on YouTube", Journal of Computer-mediated Communication, Vol. 13 No. 1, available at: http://jcmc. indiana.edu/vol13/issue1/lange.html

Larsen, M.C. (2007), “Understanding social networking: on young people's construction and co-construction of identity online", paper presented at The Society for Social Studies of Science (4S) Annual Conference, Montreal, 11-13 October.

Latour, B. (1997), "Where are the missing masses? The sociology of a few mundane artifacts", in Bijker, W.E. and Law, J. (Eds), Shaping Technology/Building Society: Studies in Sociotechnical Change, MIT Press, London. 
ITP

21,3

314

Light, B. (2007), "Introducing masculinity studies to information systems research: the case of Gaydar", European Journal of Information Systems, Vol. 16 No. 5, pp. 658-65.

Livia, A. (2002), "Public and clandestine: gay men's pseudonyms on the French Minitel", Sexualities, Vol. 5 No. 2, pp. 201-17.

Magnet, S. (2007), "Feminist sexualities, race and the internet: an investigation of Suicidegirls.com”, New Media and Society, Vol. 9 No. 4, pp. 577-602.

Myers, M.D. (1999), "Investigating information systems with ethnographic research", Communications of the Association for Information Systems, Vol. 2 No. 23, pp. 1-20, available at: http://cais.aisnet.org/.

Person, E.S. (1980), "Sexuality as the mainstay of identity: psychoanalytic perspectives", Journal of Women in Culture and Society, Vol. 5 No. 4, pp. 605-30.

Rogers, A. (2005), "Men's magazines and the mastering of intimacy", Men and Masculinities, Vol. 8 No. 2, pp. 175-94.

Röhle, T. (2007), "Desperately seeking the consumer: personalized search engines and the commercial exploitation of user data", First Monday, Vol. 12 No. 9, available at: http:// firstmonday.org/issues/issue12_9/rohle/index.html

Rubin, G. (1984), "Thinking sex: notes for a radical theory of the politics of sexuality", in Vance, C.S. (Ed.), Pleasure and Danger: Exploring Female Sexuality, Routledge and Kegan Paul, New York, NY.

Spitz, D. and Hunter, S.D. (2005), "Contested codes: the social construction of Napster", The Information Society, Vol. 21 No. 4, pp. 169-80.

Stewart, J. and Williams, R. (2005), "The wrong trousers? Beyond the design fallacy: social learning and the user", in Rohracher, H. (Ed.), User Involvement in Innovation Processes: Strategies and Limitations from a Socio-technical Perspective, Profil, Wien.

Sunday Times Magazine (2006), "Downloading Mr Right”, 15 January, pp. 18-25.

Trauth, E.M. (2002), "Odd girl out: an individual differences perspective on women in the IT profession”, Information Technology and People, Vol. 15 No. 2, pp. 98-118.

Wajcman, J. (1991), Feminism Confronts Technology, Polity Press, Oxford.

Walsham, G. (2000), “Globalization and IT: agenda for research”, in Baskerville, R., Stage, J. and De Gross, J.I. (Eds), Organizational and Social Perspectives on Research and Practice in Information Technology, Kluwer Academic Publishers, Boston, MA.

Weeks, J. (1985), Sexuality and its Discontents: Meanings, Myths and Modern Sexualities, Routledge and Kegan Paul, London.

Wellman, B. (1996), “Are personal communities local? A Dumptarian consideration”, Social Networks, Vol. 18 No. 4, pp. 347-54.

\section{Corresponding author}

Ben Light can be contacted at. b.light@salford.ac.uk

To purchase reprints of this article please e-mail: reprints@emeraldinsight.com Or visit our web site for further details: www.emeraldinsight.com/reprints 